\title{
Parcours de la notion d'individu dans le Japon moderne
}

\section{Yoichi Higuchi}

\section{(2) OpenEdition}

1 Journals

Édition électronique

URL : https://journals.openedition.org/lettre-cdf/3061

DOI : 10.4000/lettre-cdf.3061

ISSN : 2109-9219

Traduction(s) :

Overview of the Notion of the Individual in Modern Japan - URL : https://journals.openedition.org/ lettre-cdf/2199 [en]

\section{Éditeur}

Collège de France

Édition imprimée

Date de publication : 1 mars 2015

Pagination : 44

ISSN : 1628-2329

\section{Référence électronique}

Yoichi Higuchi, «Parcours de la notion d'individu dans le Japon moderne », La lettre du Collège de France [En ligne], 39 | mars 2015, mis en ligne le 26 novembre 2015, consulté le 17 août 2022. URL : http://journals.openedition.org/lettre-cdf/3061 ; DOI : https://doi.org/10.4000/lettre-cdf.3061 


\section{Parcours de la notion d'individu dans le Japon moderne}

\author{
Le mot-clé des conférences que j'ai données au \\ Collège de France en juin 2014 est une notion qui \\ hante les intellectuels japonais depuis le milieu du \\ $x I x^{e}$ siècle, et continue de les hanter aujourd'hui : \\ celle d'individu.
}

Ce choix me paraît d'autant plus opportun et nécessaire que, d'une part, la société japonaise est en train de se défaire de l'obsession du manque d'individus, et que, d'autre part, aux yeux du constitutionnaliste que je suis, la notion d'individu se rapporte au sort de la démocratie, entendue non pas seulement comme une façon de décider au nom du demos, mais surtout comme une civilisation devant gérer la res publica tout en respectant la valeur et la dignité de l'individu. La relation entre la modernisation et la démocratie ainsi définie - ce que j'appellerais le constitutionnalisme - est une des problématiques cruciales de notre temps.

L'enjeu ne se limite pas à l'archipel de l'Extrême-Orient, car la croyance en l'individu, également liée à la philosophie universaliste des Lumières, semble largement périmée dans les milieux intellectuels d'Occident, qui tendent à réclamer la fin de la modernité. C'est pourquoi, lors de ma participation au Congrès mondial du bicentenaire de la Révolution française, j'ai osé donner le sous-titre suivant à mon exposé : " La signification profonde de 1789 pour le développement du constitutionnalisme d'origine occidentale dans le monde ». C'est dans ce contexte que le grand historien Maurice Agulhon m'a répondu, lors de la conclusion qu'il a donnée au Congrès : «Voilà qui est bien digne d'encourager les Français, ceux du moins qui sont restés amis du Droit et de la Liberté... ». Mais en dehors de l'Occident, la situation n'est pas simple non plus, car il ne s'agit pas seulement de ceux qui accusent l'impérialisme culturel de l'Occident. Quelle place le Japon prenait-il, et prend-il aujourd'hui, dans ce tableau de chassé-croisé ? Quelle est la position géoculturelle de l'archipel de l'Extrême-Orient? C'est à cette interrogation que j'ai essayé de répondre.

On observe en effet trop de cas de " modernisations » qui se font en dépit d'un manque de constitutionnalisme, voire à cause de ce manque évident. En définissant la démocratie comme «le mode d'organisation politique d'une civilisation individualiste ", le constitutionnaliste Bernard Chantebout relève trois types de réactions des civilisations extra-occiden- tales face à la démocratie entendue en ce sens. À côté des types du "refus » et de l'« échec », il a qualifié l'expérience japonaise de "synthèse de la démocratie et de la tradition ». Je peux pour ma part constater, sans tomber dans le piège d'un certain patriotisme, le bilan globalement positif de la " démocratie d'après-guerre » sous la constitution de 1946, proclamant le respect de l'individu, ainsi que certains acquis honorables de la "démocratie de Taisho », y compris sous la constitution impériale de 1889. II n'en faut pas moins se demander si la qualification de «synthèse » est ici pertinente.

En retraçant de manière sommaire l'histoire moderne tourmentée, je me suis référé aux prises de position d'intellectuels représentatifs, coincés dans la rivalité continuelle entre ce qui est ouvert à l'universel et ce qui se caractérise par une certaine " japonéité ». À la suite d'une aventure tragique, et enfin libérés de la contrainte du pouvoir militaro-théocratique de 193545 , de jeunes intellectuels essayèrent de tirer la leçon de leurs expériences douloureuses.

Distinguant deux sortes de libertés, la liberté simplement libératrice du désir et la liberté créatrice des normes, Masao Maruyama (historien des idées politiques, 1914-1996) révélait un déficit cruel de la seconde dans la tradition culturelle au Japon, et lançait l'avertissement que la « démocratie d'aprèsguerre » ne serait pas viable sans l'enracinement de cette liberté là. La notion de basso ostinato qu'il a proposée nous aide à comprendre la difficulté de l'enracinement du volontarisme individualiste que nous avons vécue. La persistance de la voix dans un registre grave, inhérent au climat de cette culture, métamorphose la mélodie dominante venue de l'extérieur. Cela peut constituer les charmes de la culture japonaise (exemple du bouddhisme depuis le vile siècle). Mais le risque est également de finir écrasé par le basso ostinato devenu retentissant (le constitutionnalisme des années 1930). Shuichi Kato (écrivain et critique, 1919-2008), à qui Nobutaka Miura a consacré la majeure partie de sa conférence au Collège de France en mars 2013, a quant à lui lancé l'idée d'une « culture métisse » ou " hybride », pour surmonter l'idée, fausse selon lui, que la modernisation équivaut à l'occidentalisation. Le défi est, pour lui, nécessaire afin de ne jamais répéter l'isolement terrible des intellectuels qui n'avaient finalement pas pu empêcher la grande catastrophe.

L'individu pourra-t-il gagner du terrain dans ce petit coin de l'Asie du nord-est? II est aujourd'hui très difficile d'y répondre précisément. -

Yoichi HIGUCHI
- M. Yoichi Higuchi a été invité par l'Assemblée des professeurs sur la proposition du Pr Anne Cheng. - Retrouvez les vidéos de ces conférences sur le site www.college-de-france.fr à la page du Pr Anne Cheng. 